\title{
Faktor penentu setting fisik aktivitas Taman Lapangan Jawa di Kota Depok
}

\author{
Moh. Sanjiva Refi Hasibuan ${ }^{1 \star}$, Ray March Syahadat", \\ 1. Prodi Arsitektur Lanskap, Fakultas Teknik Sipil dan Perencanaan, Institut Sains dan Teknologi Nasional, \\ JI. Moh. Kahfi II, Jakarta Selatan, Indonesia, 12630 \\ *E-mail: refi.arl@istn.ac.id
}

\begin{abstract}
Determining factor of physical setting of the Lapangan Jawa Park activities in Depok City. The existence of parks is one of the solutions in solving urban environmental problems. Not only has an ecological function, the park also has a social function. The Lapangan Jawa Park is one of the neighbourhood parks in Depok that is actively used by locals. One of the problems that is often encountered in neighbourhood parks is imbalance use of park design with the users needs which raises issues regarding the sustainability of the park. For this reason, an evaluation is needed to determine how well the Lapangan Jawa Park can accommodate the needs in accordance with the behavior of its users. The methods were used in this article were observation to identify park characters and observation of user behavior used the behavior setting approach. The data was analyzed descriptively using image processing software (adobe photohop). The results are obtained, there are several important things that determine the physical settings of Lapangan Java Park activities in order to achieve the sustainability i.e. corrections to the entrance space in the north area of the park, parking area needs, recalculate the number and placement for bench, and the reduction in the size of sports spaces that are not so used by the park users.
\end{abstract}

Keywords: behavior setting, evaluation, neighbourhood park, park sustainability, usser needs.

\section{Pendahuluan}

Selama 20 tahun perkembangannya, Kota Depok tumbuh sebagai sebuah kota penyangga ibukota yang memiliki letak yang cukup strategis yaitu berada di antara wilayah Bogor dan Jakarta. Letak yang strategis serta kemudahan aksesibilitas memicu perpindahan penduduk terutama para pencari kerja. Para pekerja yang sebagian besar bekerja di ibukota Jakarta memilih untuk tinggal di Kota Depok sehingga mengakibatkan Kota Depok semakin padat akan penduduk dan permukiman. Kepadatan penduduk yang tinggi ini menyebabkan ketersediaan lahan atau ruang terbuka publik semakin sempit. Selain itu, kedatangan penduduk dari daerah lain juga mengakibatkan kondisi masyarakatnya yang semakin heterogen.

Menurut Andina (2015), migrasi penduduk dan heterogenitas suku dan budaya secara tidak langsung menjadi faktor pendukung terjadinya kenakalan dan kejahatan remaja di Kota Depok. Orang tua yang sebagian besar bekerja di Jakarta mengakibatkan interaksi antara anak dengan orang tua semakin berkurang demikian juga dengan pengawasannya. Salah satu solusi yang dapat dilakukan untuk mengatasi permasalahan ini adalah dengan memperbanyak Ruang Terbuka Hijau (RTH) berupa taman di Kota Depok sebab RTH bukan hanya memiliki fungsi ekologis tetapi juga sosial (Syahadat et al., 2018; Putra et al., 2017).

Taman lingkungan atau taman ketetanggaan (neighbourhood park) dalam skala RT, RW maupun kelurahan dapat dipilih karena secara lokasi akan sangat dekat dengan tempat tinggal penduduk. Taman dapat menjadi solusi permasalahan sosial yang terjadi di dalam masyarakat karena berfungsi sebagai ruang ketiga setelah rumah dan tempat bekerja. Taman menjadi ruang publik untuk berinteraksi antar masyarakat dari suku dan budaya yang berbeda, interaksi bagi keluarga (orang tua - anak), tempat bermain dan berolahraga, serta menjadi tempat untuk berekspresi dan berkreasi. Selain masalah sosial, taman dalam bentuk dan tipologi yang beragam salah satunya yaitu taman lingkungan juga dapat mempengaruhi tingkat kualitas lingkungan permukiman (Adiatma, 2011).

Dalam perencanaan sebuah taman diperlukan analisis yang tepat terutama dalam mengakomodasi kebutuhan masyarakat yang sesuai agar segala ruang dan fasilitas yang disediakan di dalam taman dapat 
dimanfaatkan dengan baik. Taman yang memiliki karakter suasana alam yang kuat lebih disukai oleh masyarakat untuk kegiatan rekreasi. Sementara taman yang dibuat dengan pola desain yang menarik lebih diminati oleh masyarakat untuk kegiatan interaksi sosial (Dwiputra dan Ardiani, 2017; Tandal dan Egam, 2011; Fristovana dan Munandar, 2011).

Salah atu taman lingkungan yang ada di Kota Depok yang memiliki fungsi lingkungan dan sosial yaitu Taman Lapangan Jawa. Taman Lapangan Jawa yang memiliki luas $6000 \mathrm{~m}^{2}$ ini bertransformasi menjadi taman yang memiliki fasilitas yang lebih baik dari kondisi sebelumnya. Di sebelah Utara taman ini berbatasan langsung dengan Jalan Jawa dan permukiman, di sebelah Barat berbatasan dengan Jalan Pakis, SDN 4, SDN 5, SDN 6, SDN 7 Beji, dan SMP IT Al-Muqorrobin. Di sebelah Timur taman berbatasan dengan Jalan Lada, TK Indria dan permukiman, sedangkan di sebelah Selatan berbatasan dengan area TPS. Berada di tengah-tengah permukiman masyarakat (Perumnas Depok) dan dekat dengan area pendidikan menjadikan taman ini sebagai area favorit untuk tempat berkumpul bagi masyarakat sekitar. Bahkan pada peringatan hari-hari besar nasional, taman ini digunakan sebagai lapangan serbaguna untuk mengadakan kegiatan seperti shalat eid dan lomba peringatan kemerdekan 17 Agustus. Hal ini dikarenakan taman memiliki area yang cukup luas berupa lapangan rumput untuk sepak bola di dalamnya. Dalam proses perencanaannya, sempat terjadi konflik berupa aksi penolakan dari masyarakat sekitar terhadap rencana pemerintah Kota Depok dalam menata Taman Lapangan Jawa. Masyarakat khawatir mereka akan kehilangan ruang terbuka yang biasanya selalu mereka manfaatkan untuk kegiatan-kegiatan bersama. Namun, setelah dilakukan proses pendekatan yang persuasif dan pemahaman yang jelas kepada masyarakat pada akhirnya rencana penataan taman ini dapat diterima dan dilanjutkan.

Setelah diresmikan pada tahun 2019, tentu perlu dilakukan evaluasi untuk melihat sejauh mana desain taman dapat memenuhi kebutuhan penggunanya. Penelitian ini bertujuan lebih spesifik untuk melihat bagaimana pengaruh pengaturan elemen-elemen pembentuk taman Lapangan Jawa dapat memengaruhi perilaku dan aktivitas pengunjung atau pengguna taman sehingga dapat menjadi pertimbangan dalam perencanaan maupun evaluasi terhadap desain taman ketetanggaan yang ada di Kota Depok.

\section{Metode}

Penelitian ini dilakukan di Taman Lapangan Jawa yang berada di Jalan Jawa, Kecamatan Beji, Kota Depok (Gambar 1). Penelitian ini dilakukan selama 1 bulan yaitu pada September hingga Oktober 2019 yang meliputi kegiatan persiapan, pengambilan data, hingga tahapan analisis. Metode yang digunakan yaitu observasi di Taman Lapangan Jawa. Adapun data yang dikumpulkan antara lain data terkait pembagian ruang, fasilitas, dan pengamatan perilaku pengunjung terhadap setting fisik. Pada pengamatan setting fisik mengacu pada Adhitama (2013). Data yang dikumpulkan antara lain pola pergerakan manusia, titik kepadatan, dan perilaku tidak sesuai seperti yang pernah dilakukan Aderina et al. (2018). Penelitian dengan pendekatan behavior setting tidak menggunakan sampel responden tetapi langsung mengamati seluruh pengguna taman pada suatu waktu. Seluruh aktivitas sepanjang waktu yang ditentukan itu digambarkan pada peta tapak pengamatan. Pengumpulan data dilakukan pada hari libur kerja yaitu hari Minggu dan dilakukan dalam dua waktu pengamatan yaitu pagi hari dan sore hari. Pengamatan pagi hari dilakukan pada pukul 09.00-10.00 WIB dan sore hari pada pukul 16.00-17.00 WIB. Kedua waktu ini dipilih karena waktu operasional taman adalah sejak pagi hingga sore hari dan merupakan waktu paling banyak dikunjungi oleh pengguna. Data selanjutnya ditransformasi dari bentuk hardfile menjadi soffile dengan perangkat lunak pengolah gambar AdobePhotoshop dan kemudian dianalisis secara deskriptif. 


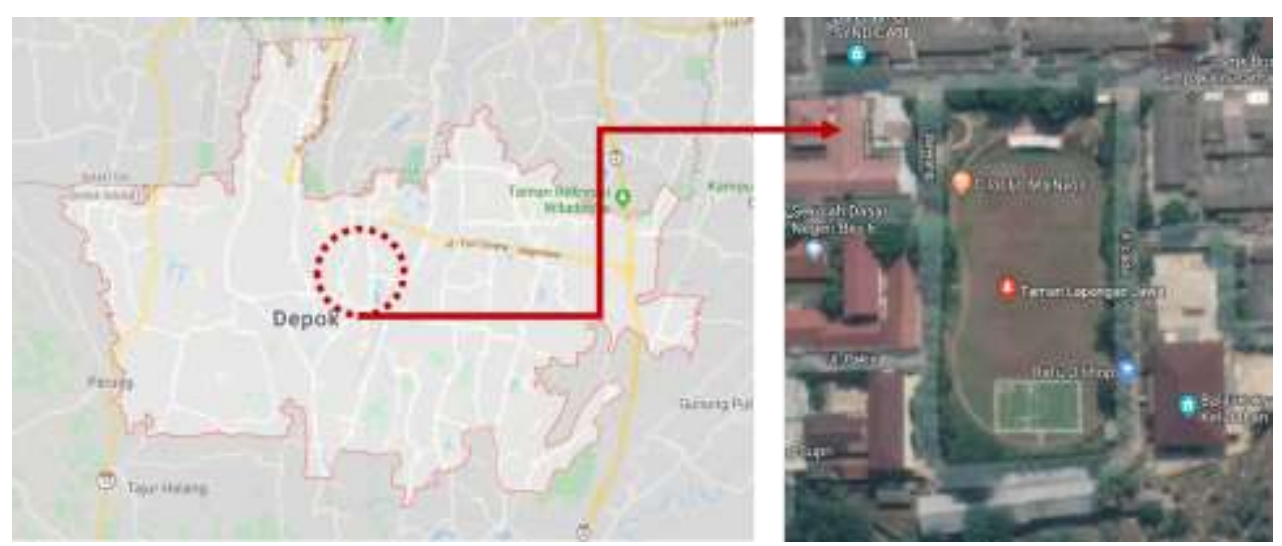

Gambar 1. Peta Lokasi Penelitian

\section{Hasil dan Pembahasan}

\subsection{Kondisi umum}

Taman Lapangan Jawa terletak di Kecamatan Beji Kota Depok. Taman ini dibangun dan diresmikan pada tahun 2019. Secara umum Taman Lapangan Jawa memiliki tujuh ruang yaitu raung penerimaan, ruang permainan, ruang transisi, ruang interaksi, ruang olahraga, ruang terbuka dan ruang servis. Failitas yang dimiliki taman ini juga cukup lengkap. Adapun fasilitas yang dimiliki taman ini antara lain plaza, permainan anak, jalur refleksi, dan shelter di area Utara. Kemudian terdapat trotoar yang berfungsi sebagai jogging track yang mengelilingi lapangan di tengah tapak beserta bangku. Selanjutnya di sebelah Selatan terdapat lapangan futsal dan gedung pemeliharaan di sebelah selatan (Gambar 2).

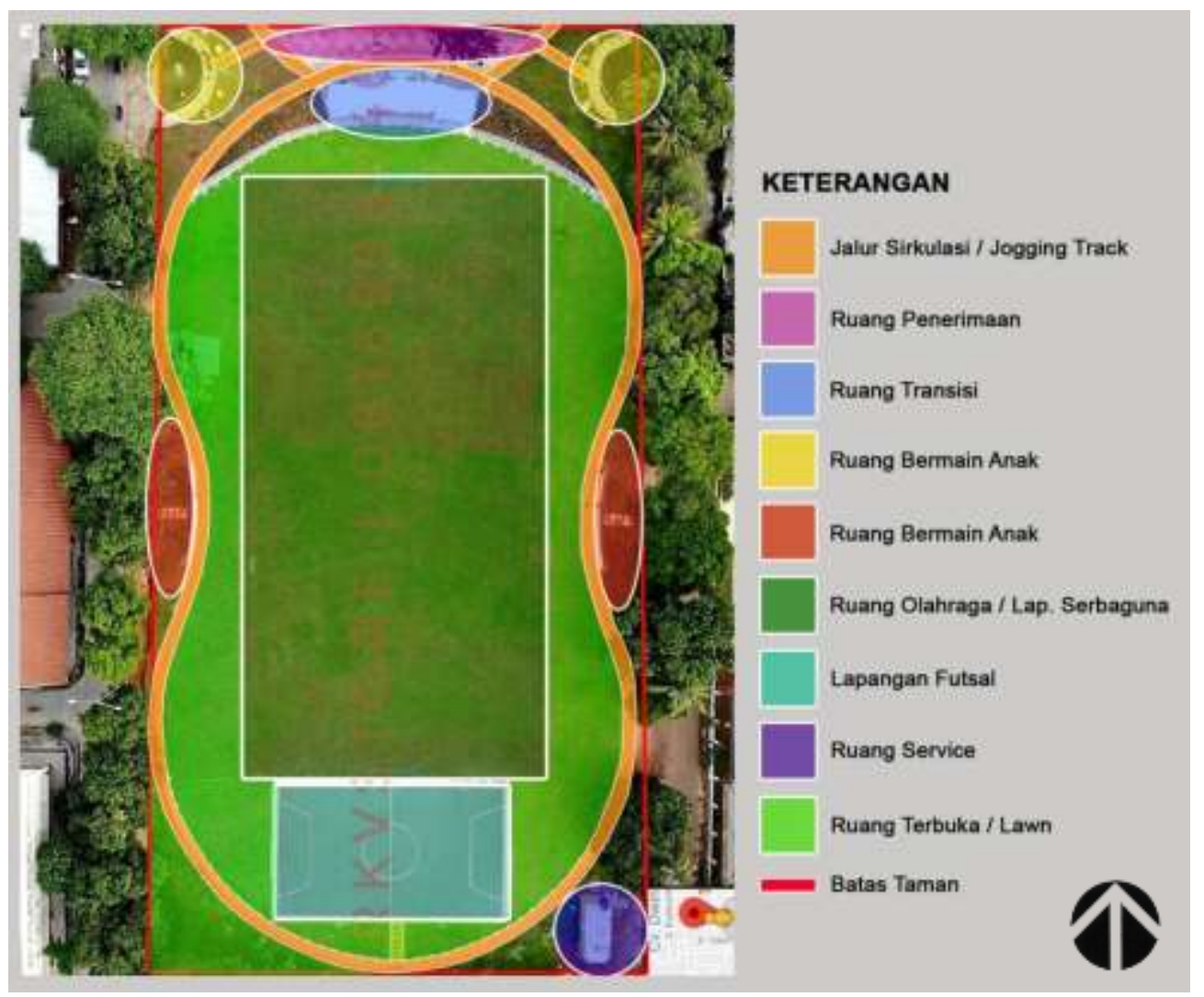

Gambar 1. Kondisi Eksisting Pembagian Ruang pada Taman Lapangan Jawa (Sumber: Foto Udara RKV Store) 


\subsection{Pola pergerakan pengunjung}

Pada pagi hari, umumnya pola pergerakan pengunjung masuk dari ruang interaksi baik pada ruang Timur maupun Barat taman. Pengunjung tidak masuk melalui ruang penerimaan yang sudah disediakan yang berada di utara karena taman ini menyediakan side entrance pada sisi Timur dan Barat yang langsung berhubungan dengan ruang interaksi. Meskipun demikian pengunjung lebih banyak keluar melalui ruang penerimaan. Pada sore hari, pengunjung umumnya masuk dan keluar melalui ruang penerimaan di Utara taman sedangkan sisanya keluar dan masuk di ruang interaksi sebelah barat. Pada sore hari pola pergerakan manusia lebih banyak mengelilingi lapangan karena memanfaatkan sirkulasinya untuk kegiatan jogging (Gambar 2).

Berdasarkan pola pergerakan pengunjung di atas baik pagi hari dan sore hari dapat dilihat bahwa pengunjung dominan bergerak pada ruang-ruang bermain anak dan ruang interaksi. Kedua ruang ini disediakan secara terpisah pada sisi Timur dan Barat guna memecah konsentrasi pengunjung agar tidak menumpuk pada satu titik. Sementara Ruang olahraga dan ruang terbuka pada sisi Selatan taman kurang optimal pemanfaatannya. Hal ini selaras dengan hasil analisis yang dilakukan oleh Dwiputra dan Ardiani (2017) bahwa distribusi kegiatan di taman didominasi oleh kegiatan rekreasi (termasuk bermain) sebesar $53,5 \%$ dan interaksi sosial sebesar $23 \%$. Jika dikaitkan dengan karakteristik pengunjung maka berdasarkan hasil pengamatan diketahui sebagian besar pengguna taman ini adalah anak-anak dan orang tua.

TAMAN LAPANGAN LAWA

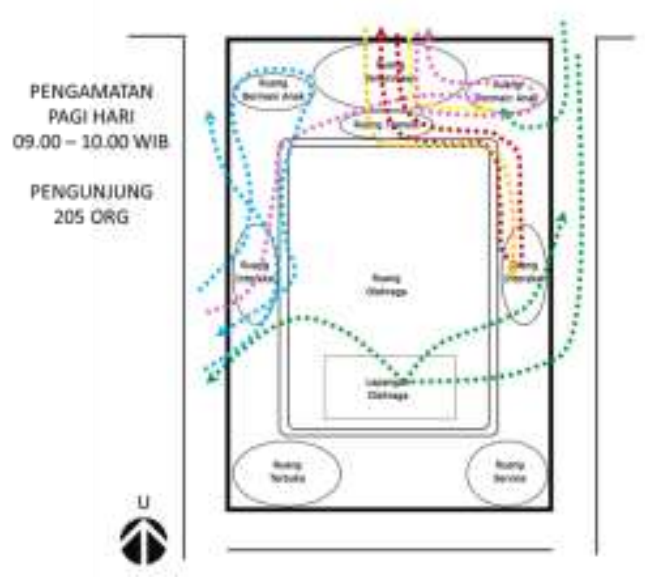

TAMAN LAPANGAN IAWA

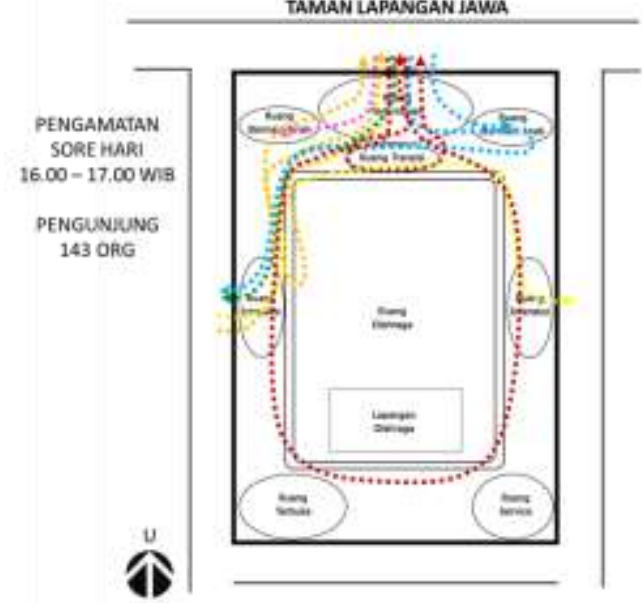

Gambar 2. Pola Pergerakan Pengunjung Pagi dan Sore Hari

Pada Taman Lapangan Jawa, fasilitas yang disediakan di ruang bermain anak antara lain alat-alat bermain sederhana seperti ayunan yang menyatu dengan fasilitas jalur refleksi dan bangku taman bagi orang tua sehingga dapat sekaligus mengawasi anak-anaknya dalam bermain. Posisi ruang bermain yang berdekatan dengan jalan dan sekolah (SD dan TK) dan tidak adanya pagar pembatas taman menyebabkan munculnya pedagang atau masyarakat yang beraktivitas pada area ini dengan tujuan komersil untuk menarik kedatangan anak-anak seperti menyediakan alat pemainan odong-odong, melukis di atas kanvas, dan sebagainya. Hal ini menjadi salah satu faktor pendukung terjadinya pergerakan pengunjung yang tinggi di area ini. Pemetaan pergerakan pengguna taman dan identifikasi komponen lingkungan spesifik yang terkait dengan peningkatan aktivitas sangat penting dan dapat menjadi panduan bagi desainer guna menciptakan lingkungan luar yang aktif dan sehat terutama bagi anak-anak (Cosco et al. 2009).

Sementara pada ruang interaksi fasilitas yang disediakan hanya berupa bangku taman memanjang yang dapat menampung beberapa orang. Ruang interaksi ini juga berdekatan dengan akses masuk taman dari Timur dan barat yang juga dekat dengan permukiman sehingga sering dijadikan sebagai akses masuk dan keluar taman. Secara umum penataan ruang dalam Taman Lapangan Jawa sesuai dengan konsep keterbukaan (openness) yaitu open to environment and society dimana ruang tidak memiliki pagar yang membatasi dan lokasinya berada dekat dengan permukiman/masyarakat (Muhaimi dan Soemardiono, 2018). 


\subsection{Kepadatan titik kumpul}

Kepadatan titik kumpul pengunjung pada dua waktu pengamatan terlihat berbeda. Pada pagi hari kepadatan terlihat di ruang sisi Utara dan Timur (Gambar 3). Pada sore hari, kepadatan berada di ruang sisi Utara dan Barat. Kepadatan pengunjung di bagian Utara disebabkan oleh fasilitas yang terpusat pada titik tersebut. Hal ini juga didukung dengan adanya pohon yang merindangi area sehingga pengunjung nyaman untuk berkumpul di pada ruang tersebut. Selanjutnya, adanya fasilitas shelter, permainan anak-anak, jalur refleksi dan bangku-bangku taman membuat ruang ini dipadati bukan cuma anak-anak tetapi juga orang tua yang mengawasi anaknya. Kepadatan pengunjung di ruang Timur dan Barat disebabkan oleh banyaknya pengunjung yang berteduh dari sengatan sinar matahari. Mereka memanfaatkan ruang interaksi yang tersedia pada sisi Timur dan Barat dengan fasilitas berupa bangku taman yang memanjang dan mampu menampung beberapa orang. Selain itu juga terdapat pengunjung yang berteduh dengan berdiri di bawah tegakan pohon. Pohon-pohon ini merupakan pohon eksisting yang sudah tumbuh besar dengan tajuk yang cukup lebar seperti pohon Ketapang (Terminalia catappa), Glodogan Bulat (Polyalthia angustifolia), dan Tanjung (Mimusops elengi). Sementara tanaman yang ditanam pada Taman Lapangan Jawa ini yaitu jenis pohon Ketapang Kencana (Terminalia mantaly) dengan tinggi 2-2,5 m yang belum tumbuh dengan optimal. Pohon ini ditanam pada beberapa titik di sekitar ruang transisi dan ruang bermain anak.
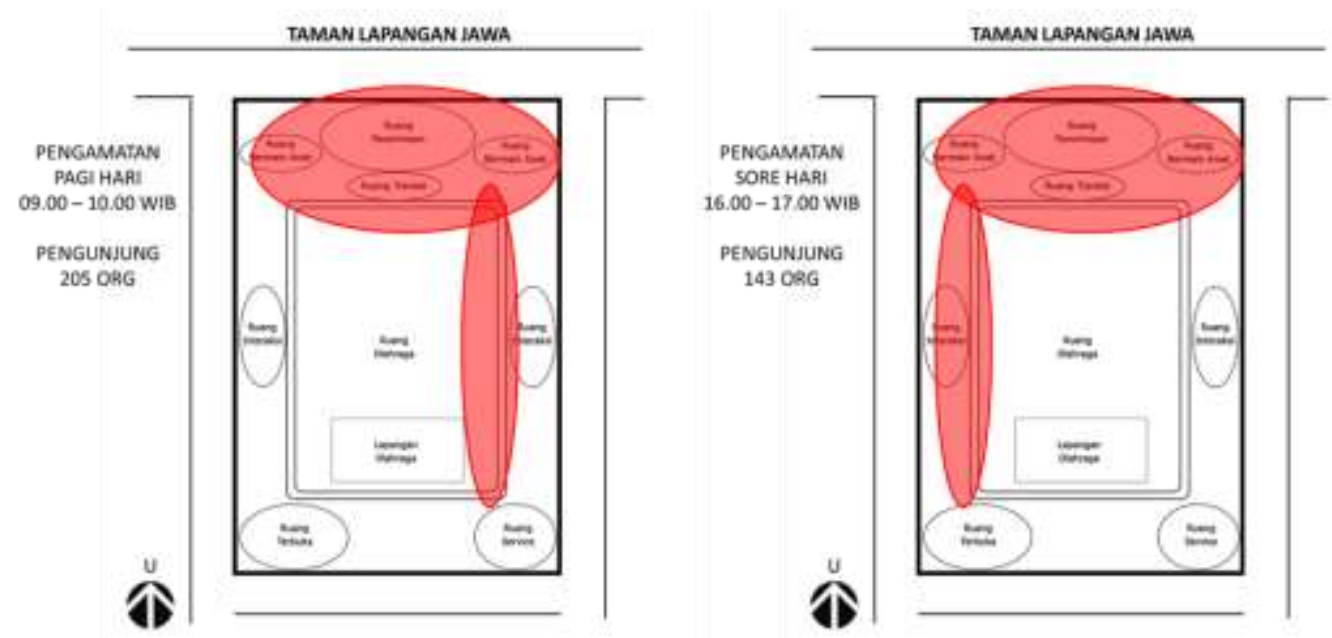

Gambar 3. Kepadatan Titik Kumpul Pengunjung Taman Lapangan Jawa

\subsection{Perilaku tidak sesuai}

Aktivitas berupa perilaku yang tidak sesuai berdasarkan hasil pengamatan paling banyak terjadi pada bagian Utara dan Timur taman. Perilaku tidak sesuai pada area Utara didominasi oleh parkir sembarangan dan pedagang liar. Tidak tersedianya area parkir untuk kendaraan mengakibatkan pengunjung taman terpaksa memarkirkan kendaraan roda duanya di pinggir taman dekat dengan ruang penerimaan sehingga secara visual cukup mengganggu dan menghalangi akses masuk pengunjung. Beberapa pengunjung juga memarkirkan kendaraannya di dekat ruang bermain anak di sebelah Timur taman. Sementara para pedagang liar banyak yang memanfaatkan ruang penerimaan sebagai tempat berdagang terutama pada pagi hari. Keberadaan para pedagang ini jika tidak dikendalikan akan mengganggu estetika dan fungsi ruang taman yang sudah direncanakan. Perilaku tidak sesuai yang dilakukan oleh pengguna taman pada area Timur didominasi oleh kegiatan duduk di trotoar sepanjang batas ruang olahraga. Trotoar yang merupakan jalur sirkulasi bagi pengguna untuk mengelilingi taman dan olahraga jogging akan terganggu dengan adanya perilaku pengunjung yang duduk-duduk di pinggir trotoar ini. Sementara area bangku taman sudah disediakan pada ruang interaksi dan ruang bermain anak (Gambar 4). 


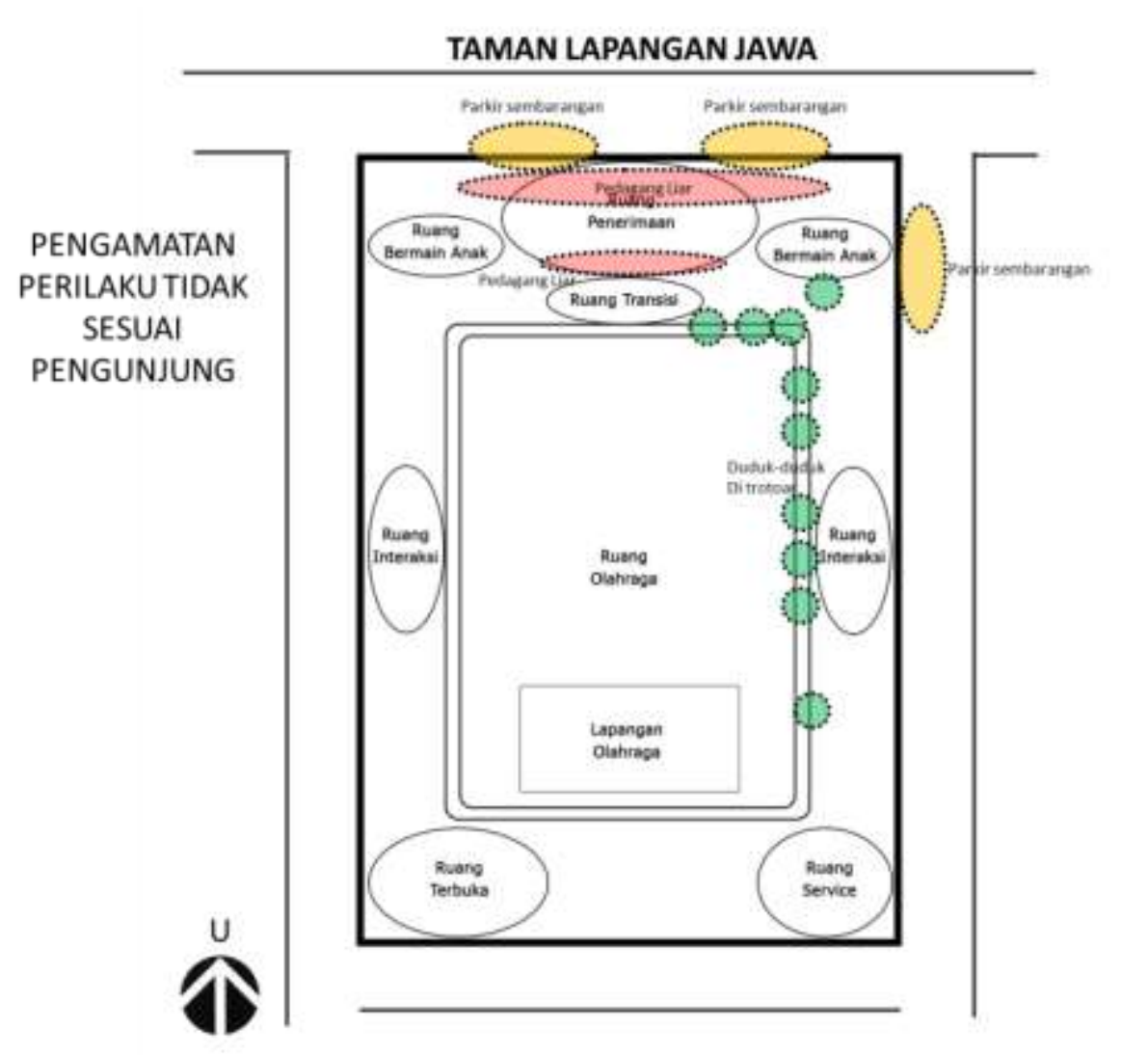

\section{Gambar 4. Sebaran Perilaku Tidak Sesuai}

Berdasarkan hasil setting perilaku yang diperoleh, terdapat beberapa hal penting yang dapat menjadi koreksi terhadap Taman Lapangan Jawa. Pertama, ruang penerimaan yang dirancang pada sisi Utara taman tidak efektif karena taman didesain dengan konsep terbuka (openness) tanpa pagar pembatas sehingga pengunjung dapat masuk ke dalam taman dari segala arah. Hal ini juga memicu terjadinya perilaku yang tidak sesuai seperti masuknya para pedagang liar ke dalam taman dan parkir kendaraan sembarangan. Untuk itu perlu dipertimbangkan penyediaan area parkir roda dua dan area khusus pedagang agar kualitas taman dapat terjaga dengan baik (Putra et al., 2018). Kedua, meskipun sudah ada fasilitas bangku, ternyata belum cukup mampu memfasilitasi pengunjung sehingga memancing pengunjung untuk berperilaku tidak sesuai dengan duduk di tempat yang tidak seharusnya. Dengan demikian, kebutuhan bangku taman perlu diperhitungkan lagi jumlahnya dan titik-titik penempatan bangku taman yang potensial juga perlu dipertimbangkan dengan baik (Permana dan Fatimah, 2017). Ketiga, ruang olahraga yang luas ternyata tidak begitu dibutuhkan. Hal ini dibuktikan dari tidak banyaknya pergerakan pengunjung di area tersebut pada pagi maupun sore hari. Lapangan ini hanya berfungsi dengan baik pada saat adanya kegiatan masyarakat yang bersifat massal. Namun keberadaan lapangan futsal cukup dimanfaatkan dengan baik karena sering digunakan oleh anak-anak dan remaja. Hal ini sejalan dengan penelitian yang dilakukan oleh Wahdah dan Dewi (2013) yang menyatakan bahwa penyediaan fasilitas lapangan olahraga dapat disesuaikan dengan fungsi maupun kebutuhan masyarakat sebagai pengguna utama.

\section{Simpulan}

Elemen Taman Lapangan Jawa memengaruhi perilaku dan aktivitas pengunjung. Namun, perencanaan dan perancangan elemen yang tidak berdasarkan analisis perilaku pengunjung, dapat menciptakan perilaku yang tidak sesuai sehingga dapat mengancam keberlanjutan taman. Beberapa hal yang dapat menjadi pertimbangan untuk menjaga keberlajutan Taman Lapangan Jawa antara lain koreksi terhadap ruang penerimaan di area utara taman, dibutuhkannya area parkir, perhitungan kembali kebutuhan dan titik penempatan fasiltas bangku, dan pengurangan luas ruang olahraga. 


\section{Ucapan Terima Kasih}

Artikel ini merupakan sebagian dari hasil penelitian berjudul Analisis Kebutuhan Elemen Hardscape pada Taman Lingkungan (Neighbourhood Park) dengan Pendekatan Behaviour Setting, yang memperoleh dana hibah Penelitian Dosen Pemula (PDP) tahun pelaksanaan 2019 oleh Kemenristek Dikti. Untuk itu, penulis mengucapkan terima kasih kepada seluruh pihak yang berperan selama kegiatan berlangsung.

\section{Daftar Pustaka}

Aderina, L., Syahadat R. M, \& Putra P. T. 2018. Perilaku pengguna ruang publik di Kompleks Militer Batalyon Artileri Medan 10 Bogor. Tesa Arsitektur, 16 (1):1-10.

Adhitama, M. S. 2013. Faktor penentu setting fisik dalam beraktifitas di ruang terbuka publik: studi kasus Alun - Alun Merdeka Kota Malang. RUAS, 11(2):1-9.

Adiatma, I. 2011. Hubungan Ruang Terbuka Hijau dengan Kualitas Lingkungan Kawasan Permukiman. Studi Kasus: Kelurahan Tembalang, Kec. Tembalang, Kota Semarang. S Skripsi. Jurusan Perencanaan Wilayah dan Kota : Fakultas Teknik Universitas Diponegoro.

Andini, E. 2015. kejahatan sadis oleh remaja: studi kasus begal sepeda motor di Kota Depok. Aspirasi, 5(2): 145-158.

Cosco, N. G., Moore, R. C., \& Islam, M. Z. 2009. Behavior mapping: a method for linking preschool physical activity and outdoor design. Journal of the American College of Sports Medicine 513-519.

Dwiputra, I. D. \& Ardiani, N. A. 2017. Preferensi Masyarakat dalam Memilih Karakteristik Taman Kota Berdasarkan Motivasi Kegiatan. Prosiding Temu IImiah IPLBI 6, E 061-066.

Fristovana, T. \& Munandar, A. 2011, Studi behavior setting figur air dan sekitarnya; studi kasus Dunia Fantasi, Gelanggang Samudera Jaya Ancol dan Danau Ancol, Jakarta Timur. Jurnal Lanskap Indonesia, 3 (1):35-41

Muhaimi, Y. \& Soemardiono, B. 2018. Behaviour setting dalam sistem keamanan bangunan sekolah dasar. Jurnal Sains dan Seni Pomits, 7(1):2337-3520.

Permana, I. A. \& Fatimah, I. 2017. Redisign taman kota Kabupaten Bogor dengan pendekatan urban landscape design. Jurnal Arsitektur Lansekap, 3(1):39-48.

Syahadat, R. M., Putra, P. T., Ramadanti, P., Radnawati, D., \& Nurisjah, S. 2018. Identifikasi keanekaragaman hayati Kota Depok, NALARs, 17 (1):29-38.

Putra, P. T., Syahadat, R. M., Radnawati, D., \& Nurisjah, S. 2017. Buku Panduan Pengelolaan Taman Kota Depok, IALI, Jakarta.

Putra, R. T., Ramadanti, P., Thoifur, D. M., Hestiningsih, H., Ramadhan R. R., Syahadat, R. M., \& Putra, P. T. 2018. Ecomparism, sebuah konsep perencanaan wisata Pantai Teloek Dalam - Bintan, Provinsi Kepulauan Riau. Jurnal Arsitektur Lansekap, 4(2):233-242.

Tandal, A. L. \& Pingkan, P. P. 2011. arsitektur berwawasan perilaku (behaviorisme). Media Metrasain, 8 (1): 53-67.

Wahdah L. \& Dewi, D. I. K. 2013. Pemenuhan lapangan olahraga di lingkungan permukiman Kota Slawi Kabupaten Tegal. Jurnal Teknik PWK, 2(2):281-292. 